\title{
Application of effective media theory in the characterization of the hygrothermal performance of masonry
}

\author{
Z. Pavlík, E. Vejmelková, L. Fiala, M. Pavlíková \& R. Černý \\ Department of Materials Engineering and Chemistry, \\ Faculty of Civil Engineering, Czech Technical University in Prague, \\ Czech Republic
}

\begin{abstract}
Hygric and thermal properties of several types of materials which are used in reconstructions of historical stone masonry on Czech territory are experimentally measured at first. The obtained data are then subjected to a homogenization procedure, and the effective heat and moisture transport and storage parameters of the typical fragment of masonry are calculated. For the homogenization, a mixing model originally derived for applications in dielectric studies was employed taking into account the theoretical bounds of the investigated material parameters. The obtained data can find use in damage assessment of historical masonry using methods of computational simulations and analysis.
\end{abstract}

Keywords: hygric properties, thermal properties, historical stone masonry, argillite, sandstone, lime-based plaster, homogenization techniques.

\section{Introduction}

The hygrothermal behaviour of climatically exposed components and structures of historical buildings is related to the hygric, thermal, mechanical and other physical and chemical properties of inbuilt materials. Their knowledge represents necessary information for the understanding of the building performance as well as the first step in avoiding damage, degradation or the undue heat loss from the constructions.

The damage assessment of historical masonry and other structures due to the negative effects of moisture and temperature can be done effectively by means of mathematical and computational modelling. In this way, the time development of 
moisture and temperature fields can be obtained which is a crucial for a proper assessment of possible future damage [1]. Their prediction is a very important task when preserving historical bridges and buildings or insulating existing buildings and components. The moisture and temperature values can be then assigned to the mechanical properties and to the risk of consequent damage. For instance Charles Bridge in Prague, Czech Republic, which was subjected to reconstruction works lately, is a typical example of extensive damage mostly brought about by temperature and moisture impacts.

For the effective application of computational modelling in the buildings' performance analysis, there is necessary complete knowledge of material properties of applied materials as well as of initial and boundary conditions of simulations. As the initial conditions for the hygric and thermal analysis, the moisture and temperature fields experimentally measured in the investigated structure can be used. Boundary conditions of the computer simulations are given by the climatic loading that can be simply adopted using meteorological data.

In the technical practice, simplified calculations of building structures' behaviour are very often used. Here, in the computational simulations of heat and moisture transport processes, brick or stone masonry is often understood as a single material, the brick or stone itself. This simplification may work reasonably well when the properties of the brick or stone and the mortar are similar. However, this may not always be the case in some historical buildings, where low-quality mortars were often used [2]. On that account, the results of such calculations are diverse from the real state of the buildings, and cannot be effectively used for estimation of some appropriate materials' damage and problems in hygrothermal behaviour. Therefore, solution of this problem must be found in order to improve the accuracy and reliability of computational modelling of building structures performance.

There are two ways how to meet the above given requirements on reliability and accuracy of computational simulation of heat and moisture transport. The first possibility is the use of sophisticated simulation tools that allow discretization of studied structure in such resolution, that all the properties of inbuilt materials can be assigned to the specific places of the structure. Although this procedure is generally correct, it is too complex and sophisticated for wider application in engineering practice, especially in case of conservationists of historical buildings that are usually well oriented in materials' problems without knowledge of methods of computational modelling.

The second, and probably the most straightforward way to solve the problem of differences in the properties of the particular components of masonry is the utilization of the effective media theory. This procedure we introduce in the presented work as an effective tool for simplification of computational modelling of transport processes in the masonry. Application of homogenization principles produces the macroscopic equations which may be used when analyzing the masonry as a whole. In these equations, the effective parameters are used instead of the parameters of the brick or stone. 
Quite apparently, the homogenization process cannot be done without the exact knowledge of the properties of all materials constituting the masonry and of the amount of each material in the analyzed wall. Therefore, the experimental measurement of all the material parameters characterising the process of heat and moisture transport and accumulation in inbuilt masonry materials is necessary at first. These data are than implemented in the mixing models based on effective media theory, and the effective thermal and hygric parameters of the whole masonry can be calculated.

\section{Studied materials}

Two types of stones that were in the past often used in Czech region as bearing masonry materials are analysed together with lime-based mortar with pozzolana admixture.

Many historical buildings in the Czech Republic were built using similar kinds of sandstone. Siliceous raw-grained sandstone was usually used for historical architectural constructions (walls, portals, window frames) for its strength. Ornamental parts of the architecture (gothic flowers, romantic shells) and sculptures (from the Romanesque period up to now) were made of finegrained calcite-argillaceous sandstone. In this work, sandstone from Mšené-lázně quarry, Czech Republic, is chosen. It is fine-grained psamitic equigranular rock, about $95 \%$ of which is made up of suboval quartz clasts. Other mineral grains are present only as minorities (tourmaline, epidote, muscovite and zircone). Quartz grains reach up to $0.1 \mathrm{~mm}$ in diameter, but those of muscovite are larger, up to $0.3 \mathrm{~mm}$ [3]. The matrix is formed by clay minerals (mainly kaolinite).

Also the argillite was very popular material in historical architecture. It was used for sacral as well as for secural buildings, flagstone pavements, roof slabs, and facing. The studied argillite is coming from quarry Džbán, Czech Republic. Its main constituents are illite, calcite, minerals on the basis of $\mathrm{SiO}_{2}$ having granularity $0.3-0.15 \mathrm{~mm}$, feldspar, and mica, whereas rigid materials form $40-$ $60 \%$ of argillite volume.

Within the reconstruction of historical buildings, renewal and restoration of interior and exterior plasters and mortars is often done. From the point of view of a historian, it is not acceptable to use lime-cement mortars in Romanesque, Gothic, Renaissance, and Baroque buildings. However, the pure lime-based plaster does not exhibit sufficient resistivity against moisture action. On that account, proper hydraulic admixtures must be used that enhance the durability of mortars. These materials must have similar composition as the historical materials and they have to be applicable by the original technological processes.

As the chemical analyses of many plasters from historical buildings show, the past centuries external plasters that are preserved until today contain products formed by lime reaction with pozzolanic or hydraulic admixtures. Pozzolanic admixtures appeared to have positive effect on properties of lime binder in the past. On that account, lime-based mortar with metakaolin addition as pozzolana admixture was chosen. The composition of the lime-metakaolin plaster was as 
follows: hydrated lime - $400 \mathrm{~g}$, metakaolin - $80 \mathrm{~g}$, natural quartz sand with continuous granulometry 0 to $2 \mathrm{~mm}-1440 \mathrm{~g}$, and water $-480 \mathrm{~g}$.

\section{Experimental methods}

Basic material properties of all tested materials were determined at first. Bulk density and matrix density were measured using gravimetric method and helium pycnometry, and then total open porosity was calculated. The samples' dimensions for these measurements were 40 × 40 × $20 \mathrm{~mm}$.

For determination of water vapour transmission properties we applied cup method, according to the European standard EN ISO 12571 [5]. The measurements were carried out in steady state under isothermal conditions. We used dry cup arrangement of the experiment. Here, the sealed cup with the studied material sample containing burnt $\mathrm{CaCl}_{2}(0 \%$ relative humidity $)$ was placed in a controlled climatic chamber at $25 \pm 0.5^{\circ} \mathrm{C}$ and $50 \%$ relative humidity and it was weighed periodically. The circular samples had diameter $95 \mathrm{~mm}$ and thickness of $20 \mathrm{~mm}$. The steady state values of mass gain were utilized for the determination of the water vapour permeability. On the basis of measured water vapour permeability, the water vapour diffusion coefficient and water vapour resistance factor were calculated using the simple formulas given in $[6,7]$.

For determination of moisture diffusivity as function of moisture, the moisture profiles were measured at first. The measurements were done on samples having dimensions of $40 \times 20 \times 300 \mathrm{~mm}$ in 1-D experimental arrangement of water transport. The moisture content in specific position in sample was measured by capacitance technique calibrated by gravimetric method. The moisture dependent moisture diffusivity was then calculated using inverse analysis of measured moisture profiles by means of Boltzmann-Matano treatment [8].

In the sorption isotherm measurement, the samples were placed into the desiccators with different salt solutions to simulate different values of relative humidity. The mass of samples was measured in specified periods of time until steady state value of mass was achieved. Then, the volumetric moisture content was calculated and sorption isotherm of each tested material was plotted.

The thermal conductivity as the main parameter of heat transport was determined using the commercial device ISOMET 2104 (Applied Precision, Ltd.). ISOMET 2104 is a multifunctional instrument for measuring thermophysical parameters which is based on the application of an impulse technique and is equipped with various types of optional probes. Thermal conductivity was measured in the moisture range from the dry state to full water saturation on the $70 \mathrm{~mm}$ cubes.

\section{Effective media theory and homogenization techniques}

Application of effective media theory allows determination of the properties of the whole masonry or building structure instead of parameters of the particular inbuilt materials. In terms of effective media theory, the final composite structure 
(in our case stone masonry wall) can be considered basically as a mixture of walling blocks and mortar. In more precise calculations, each of these materials can be further considered as a mixture of three phases, namely solid, liquid and gaseous phase (in four phase systems, the effect of bound water can be included) that form their matrix and porous space. There are two basic approaches that can be applied for determination of thermal and hygric properties of the stone masonry. The first possibility is to apply homogenization techniques on the moisture dependent material data of the materials involved in the masonry. This simplified procedure was used in this work. The second possibility is based on the complete knowledge of material properties of the particular components forming the porous body of the structure (dry stone, dry mortar, free water, bound water and air). From the properties of particular components and their volumetric fractions the effective properties of the stone masonry can be accessed.

On the basis of previous experience with application of homogenization techniques, we have chosen for the calculations performed in the presented work original Lichtenecker's formula that was proved to be satisfactory for evaluation of moisture dependent thermal and hygric properties of porous building materials [9]. Also the application of four phase models looks promising. However, in case of the masonry studied in this work, determination of amount of bound water represents very complex problem.

The Lichtenecker's equation adjusted for the studied masonry wall assumes that the effective hygric and thermal parameter of the considered material satisfies equation

$$
p_{\text {eff }}{ }^{k}=f_{b} p_{b}{ }^{k}+f_{m} p_{m}{ }^{k}
$$

where $p_{\text {eff }}$ is calculated effective parameter of masonry, $f_{b}$ volumetric fraction of walling blocks in masonry, $f_{m}$ volumetric fraction of mortar, $p_{b}$ measured material parameter of walling block, $p_{m}$ measured parameter of mortar, and $k$ is free parameter describing basically the path from the anisotropy at $k=-1.0$ to another anisotropy at $k=1.0$. However, the Lichtenecker's equation may be also applied for isotropic materials. On the basis of previous experience, we have used the value of the parameter $k=0$.

The effective parameters of multi-phase material cannot exceed the bounds given by the parameters of particular fractions of its constituents. Here, the Wiener bounds according to the Wiener's original work were used [9]. These bounds can be expressed by the following relations

$$
p_{\text {eff }}=\frac{1}{\sum_{i=1}^{n} \frac{f_{i}}{p_{i}}},
$$




$$
p_{\text {eff }}=\sum_{i=1}^{n} f_{i} p_{i},
$$

where Eq. (2) represents the lower limit and (3) the upper limit of the investigated effective material parameter $\left(f_{i}\right.$ is the volumetric fraction of the particular phase, in our case argillite, sandstone and mortar), $p_{i}$ its material parameter).

\section{Studied masonry}

For application of homogenization theory for the evaluation of the effective hygric and thermal parameters of masonry, the typical fragment of the wall was constructed in a simplified way similar to common brick masonry as shown in Figure 1.

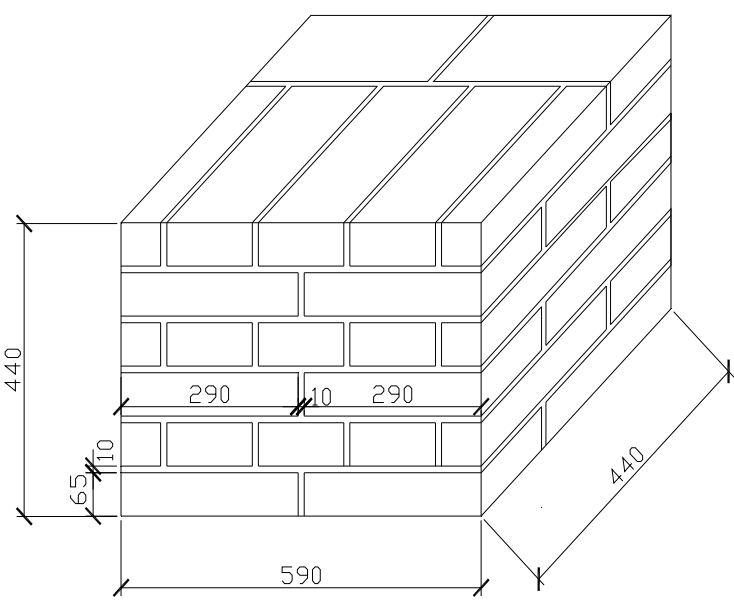

Figure 1: Scheme of the reference masonry wall (dimensions in $\mathrm{mm}$ ).

Using this scheme, the volumetric fractions of the particular materials in the wall were calculated. The volumetric fraction of walling materials is equal to 0.824 , whereas the volumetric participation of mortar is 0.176 . Within the calculations, effective parameters of two different walls were accessed. The studied walls consisted always of lime based metakaolin mortar, and of one walling material, nominally sandstone or argillite.

\section{Results and discussion}

Basic properties of all tested materials are summarized in Table 1. Each result represents the average of five measured values. All the studied materials have 
proved high porosity, what is very positive factor from the point of view of their presumed application in reconstruction of historical buildings.

Water vapour transmission properties of masonry materials are presented in Table 2 . We can see systematically very low values of water vapour resistance factor what is again very prospective finding for application of all tested materials in historical masonry. Since the historical masonry usually exhibits increased moisture content, there is necessary to apply within the reconstruction processes such materials that will allow moisture evaporation from the renovated structures within the warm periods of the year.

Table 1: Basic material properties of masonry materials.

\begin{tabular}{|c|c|c|c|}
\hline material & $\begin{array}{c}\text { bulk density } \\
\left(\mathrm{kg} / \mathrm{m}^{3}\right)\end{array}$ & $\begin{array}{c}\text { matrix density } \\
\left(\mathrm{kg} / \mathrm{m}^{3}\right)\end{array}$ & $\begin{array}{c}\text { total open } \\
\text { porosity }(-)\end{array}$ \\
\hline sandstone & 1807 & 2627 & 0.31 \\
\hline argillite & 1353 & 2235 & 0.39 \\
\hline $\begin{array}{c}\text { lime-metakaolin } \\
\text { mortar }\end{array}$ & 1690 & 2620 & 0.35 \\
\hline
\end{tabular}

Table 2: Water vapour transmission properties of masonry materials.

\begin{tabular}{|c|c|c|c|}
\hline & \multicolumn{3}{|c|}{ dry cup arrangement, $0-50 \%$} \\
\hline material & $\begin{array}{c}\text { water vapour } \\
\text { permeability (s) }\end{array}$ & $\begin{array}{c}\text { water vapour } \\
\text { diffusion } \\
\text { coefficient }\left(\mathrm{m}^{2} / \mathrm{s}\right)\end{array}$ & $\begin{array}{c}\text { water vapour } \\
\text { resistance factor } \\
(-)\end{array}$ \\
\hline sandstone & $2.4 \mathrm{E}-11$ & $3.3 \mathrm{E}-06$ & 7.0 \\
\hline argillite & $2.9 \mathrm{E}-11$ & $4.1 \mathrm{E}-06$ & 5.7 \\
\hline $\begin{array}{c}\text { lime-metakaolin } \\
\text { mortar }\end{array}$ & $1.8 \mathrm{E}-11$ & $2.5 \mathrm{E}-6$ & 10.1 \\
\hline
\end{tabular}

In Table 3, there are presented the effective diffusion parameters of studied stone masonry calculated on homogenization principles. For verification of calculated results, also the limiting bounds of effective parameters are presented. Looking at the obtained data of water vapour transmission properties, one can see that all the effective parameters lie between the Wiener's bounds which basically verifies their correctness.

Effective moisture diffusivity as function of moisture content is given in Figures 2, 3. We can see high dependence of this moisture transport parameter on moisture content. This materials' behaviour significantly affects the hygrothermal performance and consequently the durability. Systematically, the highest moisture diffusivity exhibits sandstone. Its highly porous structure formed by high radius pores allows fast liquid moisture transport in comparison with argillite that is characteristic also by high total open porosity, but its pore size is much smaller and structure more fine-grained. 
Table 3: $\quad$ Water vapour transmission properties of stone masonry.

\begin{tabular}{|c|c|c|c|}
\hline \multicolumn{4}{|c|}{ Sandstone wall - homogenization, dry cup arrangement $-0-50 \% \mathrm{RH}$} \\
\hline & $\begin{array}{c}\text { water vapour } \\
\text { permeability (s) }\end{array}$ & $\begin{array}{c}\text { water vapour } \\
\text { diffusion } \\
\text { coefficient }\left(\mathrm{m}^{2} / \mathrm{s}\right)\end{array}$ & $\begin{array}{c}\text { water vapour } \\
\text { resistance } \\
\text { factor }(-)\end{array}$ \\
\hline Wiener's lower bound & 2.29E-11 & $3.11 \mathrm{E}-06$ & 7.40 \\
\hline Wiener's upper bound & $2.24 \mathrm{E}-11$ & $3.05 \mathrm{E}-06$ & 7.55 \\
\hline Lichtenecker model, $\mathrm{k}=0$ & $2.27 \mathrm{E}-11$ & $3.08 \mathrm{E}-06$ & 7.47 \\
\hline \multicolumn{4}{|c|}{ Argillite wall - homogenization, wet cup arrangement $-0-50 \% \mathrm{RH}$} \\
\hline & $\begin{array}{c}\text { water vapour } \\
\text { permeability (s) }\end{array}$ & $\begin{array}{c}\text { water vapour } \\
\text { diffusion } \\
\text { coefficient }\left(\mathrm{m}^{2} / \mathrm{s}\right)\end{array}$ & $\begin{array}{c}\text { water vapour } \\
\text { resistance } \\
\text { factor }(-)\end{array}$ \\
\hline Wiener's lower bound & $2.74 \mathrm{E}-11$ & $3.73 \mathrm{E}-06$ & 6.17 \\
\hline Wiener's upper bound & $2.61 \mathrm{E}-11$ & $3.55 \mathrm{E}-06$ & 6.47 \\
\hline Lichtenecker model, $\mathrm{k}=0$ & $2.69 \mathrm{E}-11$ & $3.65 \mathrm{E}-06$ & 6.30 \\
\hline
\end{tabular}

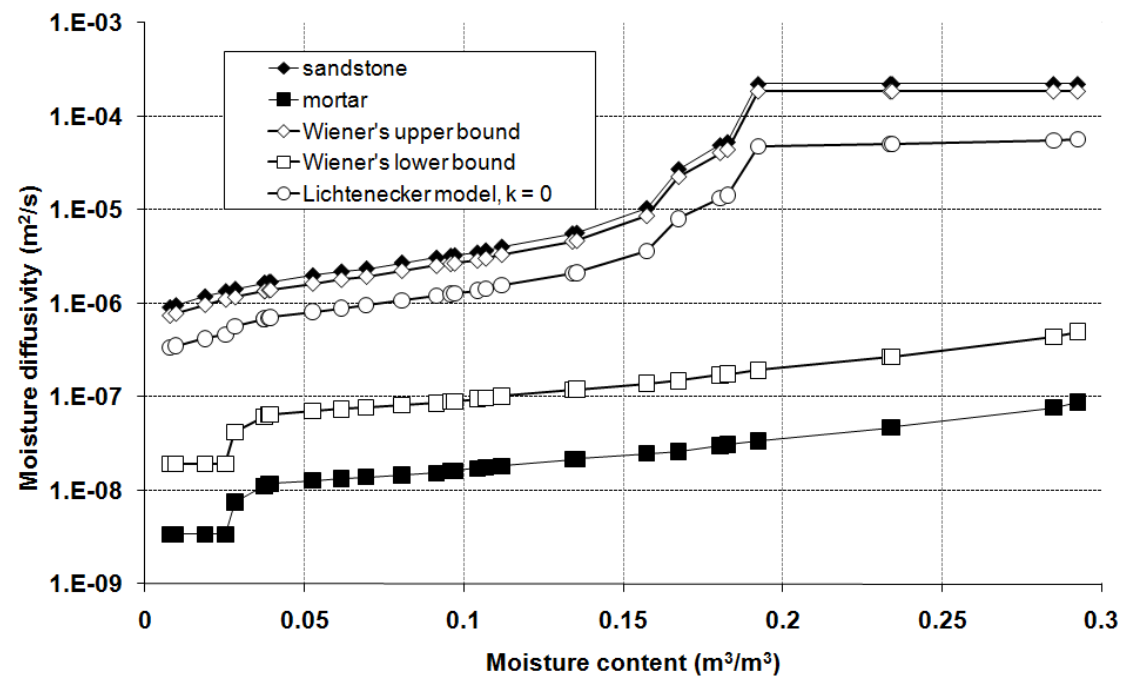

Figure 2: $\quad$ Effective moisture diffusivity of sandstone masonry.

The calculated effective sorption isotherms of studied masonry are given in Figures 4 and 5. Typically, the highest capacity for water vapour adsorption can be observed for lime-metakaolin mortar. However, in hygroscopic moisture range, the highest values of adsorbed moisture were measured for argillite. The data obtained for sandstone were systematically the lowest. 


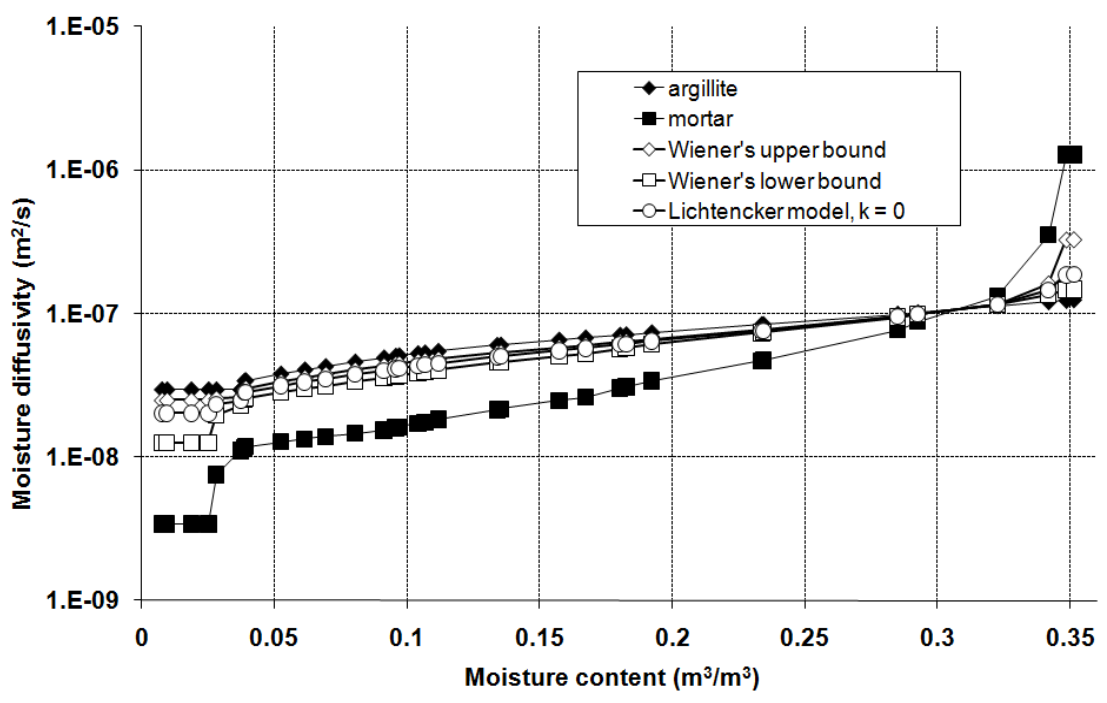

Figure 3: Effective moisture diffusivity of argillite masonry.

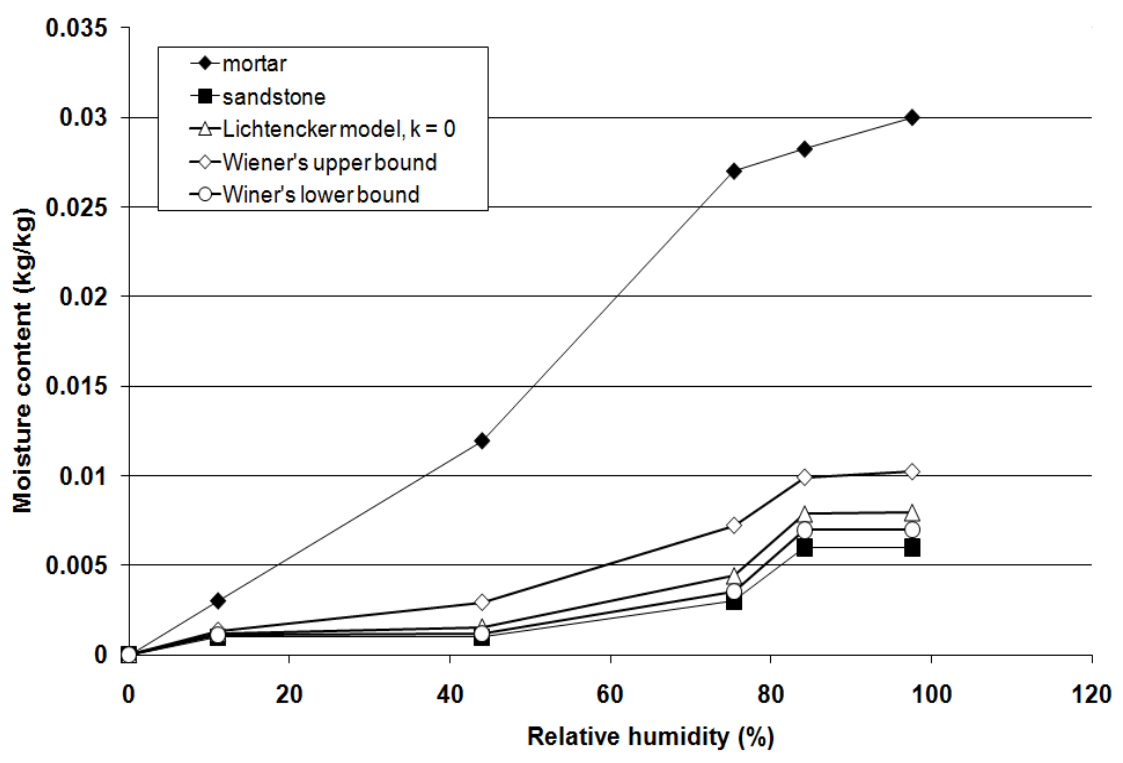

Figure 4: Effective sorption isotherm of sandstone masonry. 


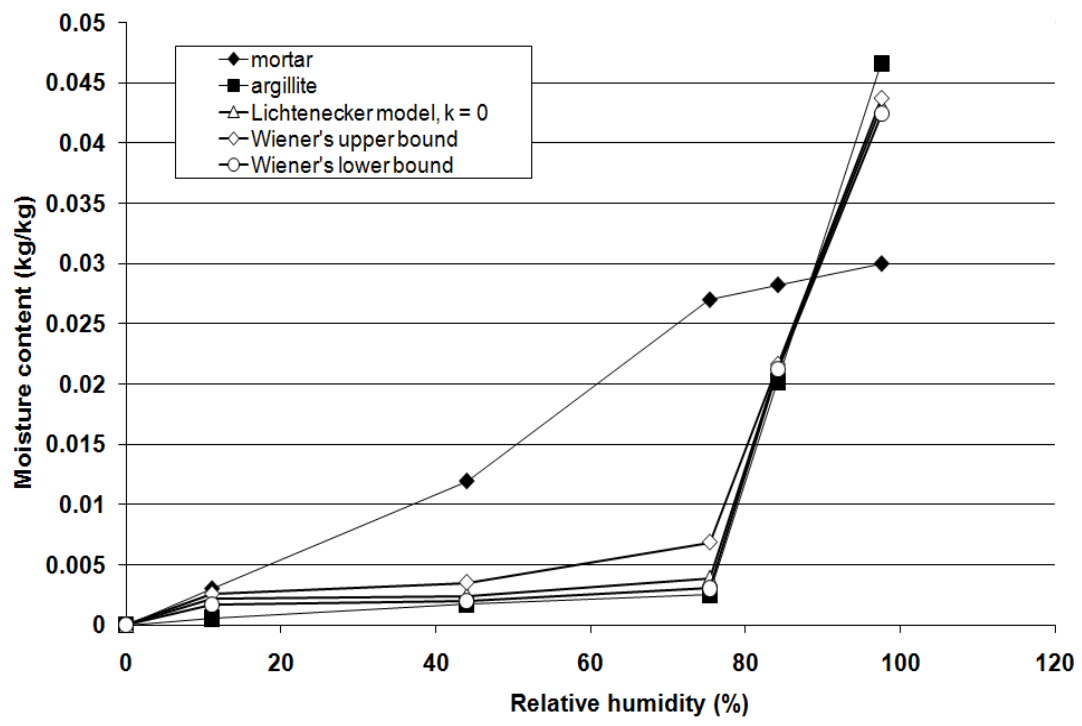

Figure 5: Effective sorption isotherm of argillite masonry.

Measured and calculated thermal conductivity of all studied materials and two types of masonry is presented in Figures 6 and 7. The values of effective thermal conductivity in dependence on moisture content are systematically between the range of Wiener's bounds, which basically proves reliability of applied homogenization technique.

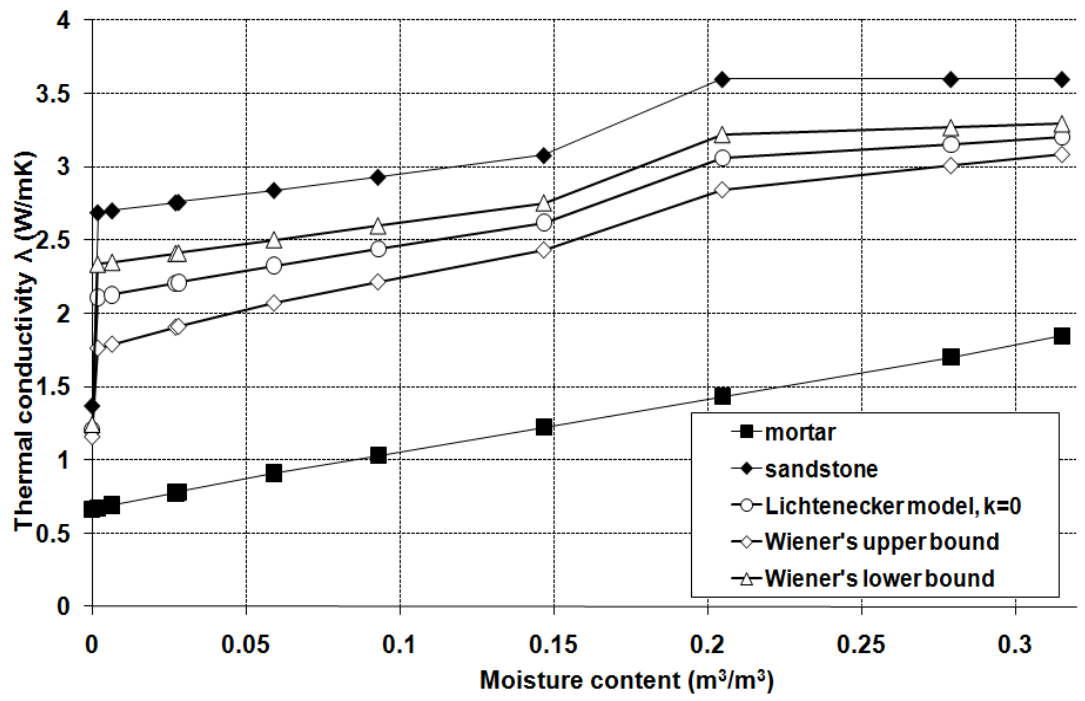

Figure 6: Effective thermal conductivity of sandstone wall. 


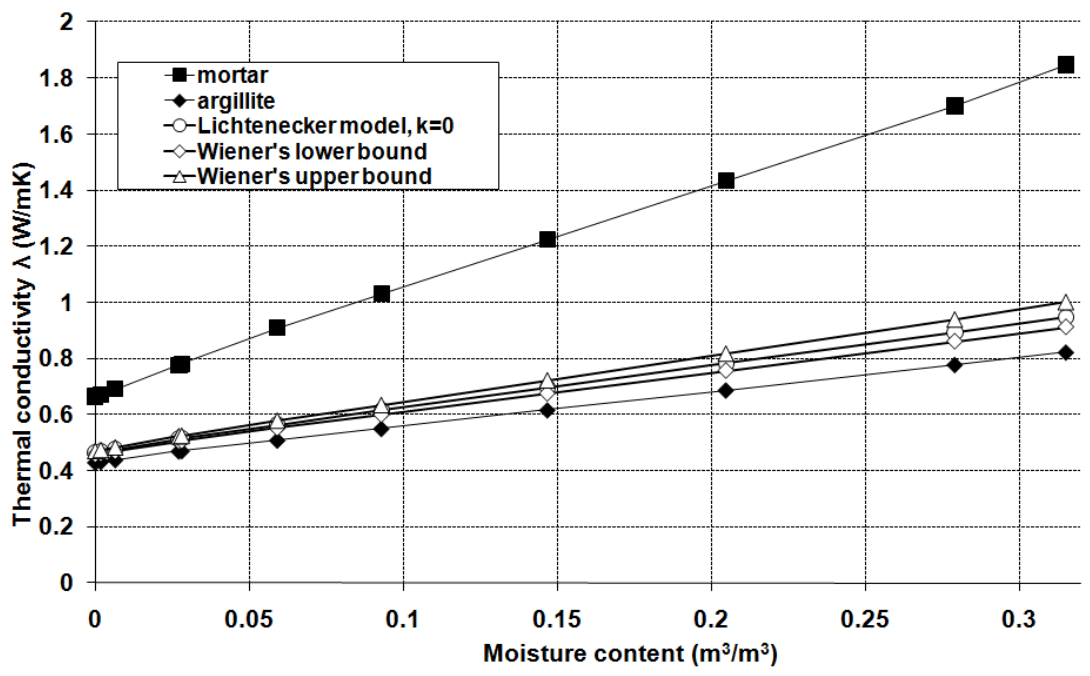

Figure 7: Effective thermal conductivity of argillite wall.

\section{Conclusions}

An example of application of homogenization technique for determination of hygric and thermal parameters of the stone masonry was introduced in the paper. The obtained results indicate that the Lichtenecker's equation may be successfully used for such type of applications. Nevertheless, there is still an open task to verify the reliability of applied homogenization model by laboratory experiments that should confirm or controvert the presented results.

\section{Acknowledgement}

This research has been supported by the Czech Ministry of Education, Youth and Sports, under project No MSM 6840770031.

\section{References}

[1] Pavlíková, M., Pavlík, Z. \& Černý, R., Hygric and Thermal Properties of Materials Used in Historical Masonry. Proc. of the $8^{\text {th }}$ Symposium on Building Physics in the Nordic Countries, Technical University of Denmark: Lyngby, pp. 903-910, 2008.

[2] Vejmelková, E., Pavlík, Z., Fiala, L., Pavlíková, M. \& Černý, R., Heat and Moisture Transport Properties of Stone Masonry Materials. Proc. of the Building Physics Symposium, Katolieke Universiteit Leuven, Leuven, pp. 113-116, 2008. 
[3] Pavlík, Z., Michálek, P., Pavlíková, M., Kopecká, I., Maxová, I. \& Černý, R., Water and Salt Transport and Storage Properties of Mšené Sandstone. Construction and Building Materials, 22(22), pp. 1736-1748, 2008.

[4] Pavlík, Z., Identification of parameters describing the coupled moisture and salt transport in porous building materials, CTU Prague, p. 145, 2009.

[5] EN ISO 12572, Hygrothermal performance of building materials and products, determination of water vapour transmission properties, the European Committee for Standardization, Brussels, 2001.

[6] JIřičková M., Application of TDR Microprobes, Minitensiometry and Minihygrometry to the Determination of Moisture Transport and Moisture Storage Parameters of Building Materials, CTU Prague, p. 102, 2004.

[7] Roels S., Carmeliet, J., Hens, H., Adan, O., Brocken, H., Černý R., Pavlík Z., Hall Ch., Kumaran K., Pel L. \& Plagge R., Interlaboratory Comparison of Hygric Properties of Porous Building Materials. Journal of Thermal Envelope \& Building Science, 27(4), pp. 307-325, 2004.

[8] Roels, S., Carmeliet, J., Hens, H., Adan, O., Brocken, H., Černý, R., Pavlík, Z., Hall, C., Kumaran, K., Pel, L., A Comparison of Different Techniques to Quantify Moisture Content Profiles in Porous Building Materials. Journal of Thermal Envelope \& Building Science, 27(4), pp. 261-276, 2004.

[9] Pavlík, Z., Vejmelková, E., Fiala, L., Černý, R., Effect of Moisture on Thermal Conductivity of Lime-Based Composites. International Journal of Thermophysics, 30(6), pp. 1999-2014, 2009. 